\title{
Testing a New Type of Fertilizer to Improve Nursery Production of Framework Tree Species for Forest Ecosystem Restoration in Northern Thailand
}

\author{
Panya Waiboonya ${ }^{1,3^{*}}$ and Stephen Elliott ${ }^{2}$
}

\begin{abstract}
${ }^{1}$ Department of Biology, Faculty of Science, Chiang Mai University, Chiang Mai 50200, Thailand

${ }^{2}$ Forest Restoration Research Unit, Department of Biology, Faculty of Science, Chiang Mai University, Chiang Mai 50200, Thailand

${ }^{3}$ Bodhivijjalaya College, Srinakharinwirot University, Tak 63110, Thailand

*Corresponding author. E-mail: panyawa@g.swu.ac.th

https://doi.org/10.12982/CMUJNS.2019.0028
\end{abstract}

Received: September 11, 2018

Revised: February 11, 2019

Accepted: February 21, 2019

\begin{abstract}
To improve planting-stock production of native forest tree species for tropical forest ecosystem restoration projects in northern Thailand, we compared a new controlled-release fertilizer, developed by NANOTEC, with our current standard fertilizer treatment for its effects on sapling growth and biomass allocation in a small-scale tree nursery. Eight species were tested: Artocarpus lacucha, Adenanthera microsperma, Acrocarpus fraxinifolius, Hovenia dulcis, Horsfieldia amygdalina, Phyllanthus emblica, Prunus cerasoides and Syzygium albiflorum, using a randomized complete block design with three treatments $x$ three replicates of nine plants per replicate for each of the eight species. The treatments were NANOTEC fertilizer, applied once at doses $0.30 \mathrm{~g}$ or $0.15 \mathrm{~g}$ per sapling, two weeks after pricking out small seedlings from germination trays into plastic bags $23 \mathrm{~cm} \times 6 \mathrm{~cm}$, compared with 0.30 $\mathrm{g}$ Osmocote ${ }^{\circledR} 13: 13: 13$ (our current most effective fertilizer treatment). Sapling growth (height, crown width and root collar diameter) was then measured over 121 days. The new NANOTEC fertilizer, at both doses, performed equally as well as Osmocote ${ }^{\circledR}$. With very few exceptions, differences in mean sapling growth performance, biomass, root:shoot ratio
\end{abstract}


and remaining nutrients $(N, P$ and $K)$ in the potting medium, among all the fertilizer treatments, were not statistically significant, for every individual species and when treatment data were combined for all species. Consequently, the locally produced NANOTEC fertilizer, at $0.15 \mathrm{~g} /$ tree, could be used as a cost-effective substitute for $0.30 \mathrm{~g}$ Osmocote ${ }^{\circledR}$, provided that its retail price is similar to or lower than that of Osmocote ${ }^{\circledR}$, when it enters mass production.

Keywords: Sapling growth, NSTDA, Sapling propagation

\section{INTRODUCTION}

The production of saplings of a wide range of native forest tree species is vital for effective forest ecosystem restoration, wherever natural regeneration in insufficiently dense to meet restoration goals. High-quality planting stock ensures high survival and growth of trees, after they have been planted out in the unfavorable conditions that prevail on deforested sites. This results in rapid achievement of the first critical milestone of forest ecosystem restoration: canopy closure and the elimination of light-demanding herbaceous weeds. Consequently, good nursery practices contribute substantially towards restoration success.

The Forest Restoration Research Unit, Department of Biology, Chiang Mai University (FORRU-CMU) has been developing effective restoration techniques since 1994. The unit adapted and further developed the framework species method to successfully and rapidly restore a diverse range of forest ecosystem types across Thailand and in some neighboring countries (Elliott et al., 2013). Originally conceived in Australia, (Goosem and Tucker, 1995), this approach attracts seed-dispersing wildlife into sites undergoing restoration (Wydhayagarn et al., 2009), which promotes rapid diversification of the understory, resulting in accelerated biodiversity recovery and carbon accumulation (Elliott et al., 2013; Kavinchan et al., 2015; Jantawong et al., 2017).

The framework species method depends on the production of highquality saplings of 20 to 30 tree species that are characteristic of the target forest ecosystem type being restored. FORRU's nurseries on Doi Suthep and at Ban Mae Sa Mai (Chiang Mai Province, northern Thailand) produce more than 50,000 trees per year for this technique. Our nursery staff germinate locallycollected seeds in germination trays, then transfer the seedlings (at the 2-node stage) into plastic bags $(23 \mathrm{~cm} \times 6 \mathrm{~cm}$ ) for growing-on. Weeding, grading, pruning and fertilizer application are carried out, as required, to produce saplings $30-50 \mathrm{~cm}$ tall by the optimum planting time (mid-June in northern Thailand). 
Approximately $0.3 \mathrm{~g}$ (10 granules) of Osmocote ${ }^{\circledR}$ (3-month, NPK 13:13:13), a controlled release fertilizer, is applied when the young seedlings are pricked out of germination trays and transferred into the plastic bags, and at 3-month intervals thereafter. The dosage of 10 granules Osmocote ${ }^{\circledR}$ (about $0.3 \mathrm{~g}$ ) every 3 months was originally recommended to FORRU-CMU staff while they were training with tree nursery managers in Queensland, Australia, where framework tree species are produced to restore seasonally dry tropical forest, under similar climatic conditions to those of northern Thailand. Subsequently, FORRU staff compared the recommended Osmocote ${ }^{\circledR}$ regime with conventional soluble fertilizer and found that, for most species, use of Osmocote ${ }^{\circledR}(0.3 \mathrm{~g}$ applied every 3 months) resulted in better growth compared with conventional use of soluble fertilizer (Jitlam, 2001; Singpetch, 2002). Since then, FORRU-CMU's standard fertilizer regime for saplings in plastic bags, has remained 10 granules of Osmocote ${ }^{\circledR}$ (13:13:13) applied every 3 months, during the standing-down period, until saplings reach the required size $(30-50 \mathrm{~cm}$ tall) (FORRU, 2006).

A new controlled-released fertilizer is being developed by the National Nanotechnology Center (NANOTEC). It has a nanocomposite coating (an alkyd resin containing modified montmorillonite clay (mMMT)) which, combined with a hydrophobic polymer layer, decelerates the solubility of fertilizer within, thus delivering a more even supply of nutrients to the plants and reducing nutrient wastage. The fertilizer shows slow $\% \mathrm{~N}$-release with a kinetic constant of 0.0804 at $40{ }^{\circ} \mathrm{C}$. Sitthisuwannakul et al. (2014) first demonstrated that regular urea fertilizer, coated with the nanocomposite, released nitrogen for up to 36 days, compared with non-coated urea fertilizer, which completely dissolves in 5 minutes in water at $40{ }^{\circ} \mathrm{C}$. Further developments of the coating now prolonged nutrient release to 3-months. The product shows positive results in the laboratory, but had not been tested on plants under more natural conditions and never on forest tree species. Consequently, the research presented here tested this new type of fertilizer and compared its performance with that of FORRU-CMU's conventional fertilizer regime.

\section{MATERIALS AND METHODS}

\section{Study species}

Experiments were performed on saplings of the indigenous forest tree species: Artocarpus lacucha, Adenanthera microsperma, Acrocarpus fraxinifolius, Hovenia dulcis, Horsfieldia amygdalina, Phyllanthus emblica, Prunus cerasoides and Syzygium albiflorum; all proven acceptable or excellent framework tree species (FORRU, 2006; Elliott et al., 2013). 


\section{Seedling Potting}

Seeds were germinated in modular germination trays. Seedlings with at least two pairs of true leaves were then transferred into black polyethylene bags $(23 \mathrm{~cm} \times 6 \mathrm{~cm})$ (1 plant per bag). A standard potting medium: forest soil, coconut husk and peanut husk (2:1:1) was used (FORRU, 2006; Elliott et al., 2013). Seedlings were prepared at least two weeks before starting the experiment, to take account of mortality due to transplantation stress, so only healthy seedlings were used in the study.

\section{Experimental Design}

The experiment was a randomized completed block design with 3 treatments, applied to 8 species, across 3 replicated blocks. Osmocote ${ }^{\circledR}(O)$ and the NANOTEC fertilizer (NF) are both slow release fertilizers, containing nitrogen, phosphorus and potassium at 13,13 , and $13 \%$ respectively. Osmocote ${ }^{\circledR}$ (0.3 gram) (O30) served as the control (since this is FORRU-CMU's triedand-tested, standard protocol), against which two doses: 0.15 and $0.30 \mathrm{~g}$ of NF were compared (NF15 and NF30), applied 2 weeks after potting. Within each replicate, plastic bags were arranged in squares of $5 \times 5$ seedlings, within which seedlings in the inner $3 \times 3$ plastic bags were used as the test plants. Seedlings in the outer rows formed a 'guard row', to ensure that the test plants were all grown under similar conditions (no corner or edge plants) and to provide buffering against external factors. In total, 225 seedlings were used in all three blocks per species, of which 81 were the test plants. In order to quantify soil nutrient availability, one extra block was set up with only media and fertilizer (no plants).

\section{Sapling Growth}

The following variables were measured for all test saplings: root collar diameter, crown width (at widest point), height, and health (on a scale 0-3) (FORRU, 2006).

Sapling relative growth rate (RGR) was calculated using the follow equation:

$(\ln \mathrm{FS}-\ln \mathrm{IS}) \times 36,500$

RGR =

No. days between measurements 
where $\ln$ FS is the natural logarithm of final sapling size and $\ln$ IS is the natural logarithm of the initial sapling size. This was done using height, root collar diameter and crown width data (RGR-H, RGR-RCD and RGR-CW respectively) (Elliott et al., 2013)

For biomass and root:shoot ratio measurements, saplings were randomly selected from each treatment and block, soil thoroughly removed and roots and shoots separated and weighed, dried (at $70^{\circ} \mathrm{C}$ until constant weight) and then weighed again. Root:shoot ratio was determined, using the equation below, at the beginning of the experiment and after 56 and 112 days respectively.

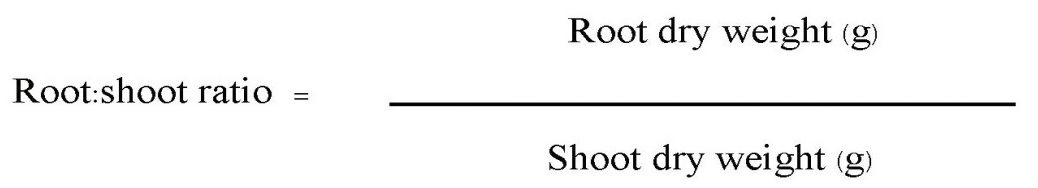

\section{Soil nutrient analysis}

Nutrient availability in the potting medium, subjected to the different fertilizer treatments, was determined at the start of the experiment and at 56 and 112 days. The potting medium was sampled from one pot from each treatment and block for each species i.e. three samples for each treatment per species. All samples were analyzed at the Central Laboratory of Department of Plant Science and Soil Science, Faculty of Agriculture CMU.

\section{Statistical analysis}

Mean relative growth rate (height, crown width and RCD), sapling biomass, root:shoot ratio and fertilizer remaining were compared among treatments for each species using ANOVA. Differences between treatment pairs were tested for significance by Tukey's HSD at $\alpha=0.05$. Statistical analyses were performed with PAST version 3.22 (Hammer et al., 2001).

\section{RESULTS}

\section{Growth and final biomass}

Fertilizer treatments did not significantly affect sapling growth and final biomass at 112 days of all species. Mean sapling dry mass of all species did not differ significantly among fertilizer treatments (Figure 1). In addition, fertilizer treatment did not affect root:shoot ratio of all species at 121 days. Differences in mean root:shoot ratios were not significant among all fertilizer treatments (Figure 2). 


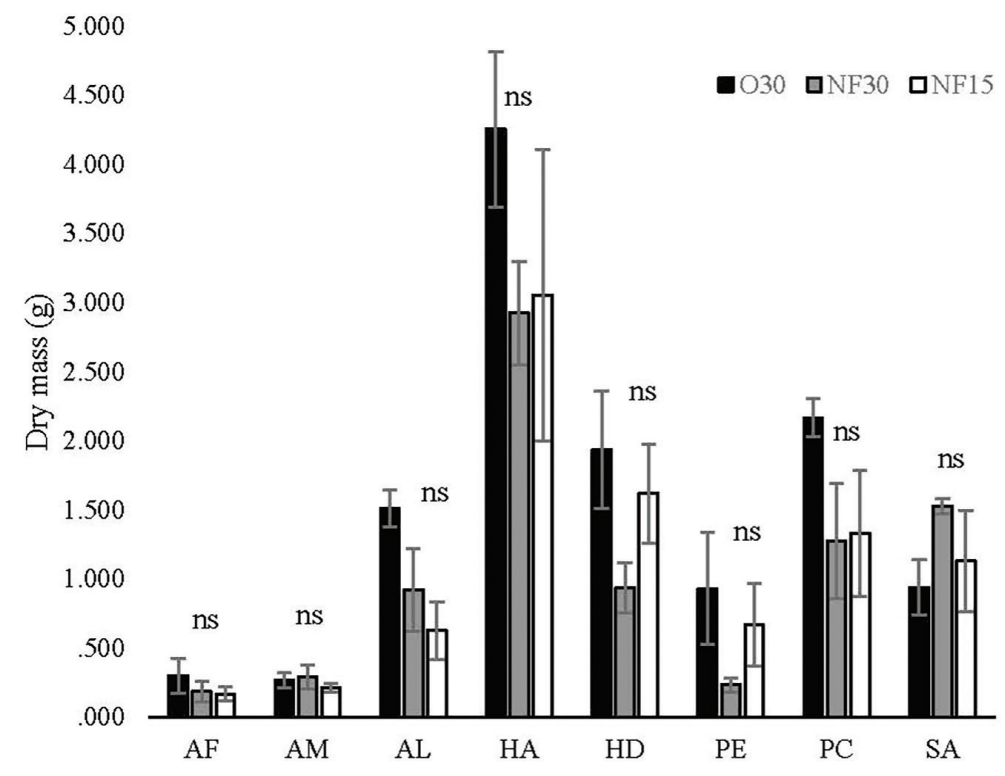

Figure 1. Effects of fertilizer treatments on mean dry mass $( \pm \mathrm{SE})$ of 8 native tree species after 121 days. Black, grey and white bars are O30, NF30 and NF15, respectively. $\mathrm{N}=3$, ns = no significant difference, $\mathrm{AF}=$ Acrocarpus fraxinifolius, $\mathrm{AM}=$ Adenanthera microsperma, $\mathrm{AL}=$ Artocarpus lacucha, $\mathrm{HD}=$ Hovenia dulcis, $\mathrm{HA}=$ Horsfieldia amygdalina, $\mathrm{PE}=$ Phyllanthus emblica, $\mathrm{PC}=$ Prunus cerasoides and $\mathrm{SA}=$ Syzygium albiflorum. 


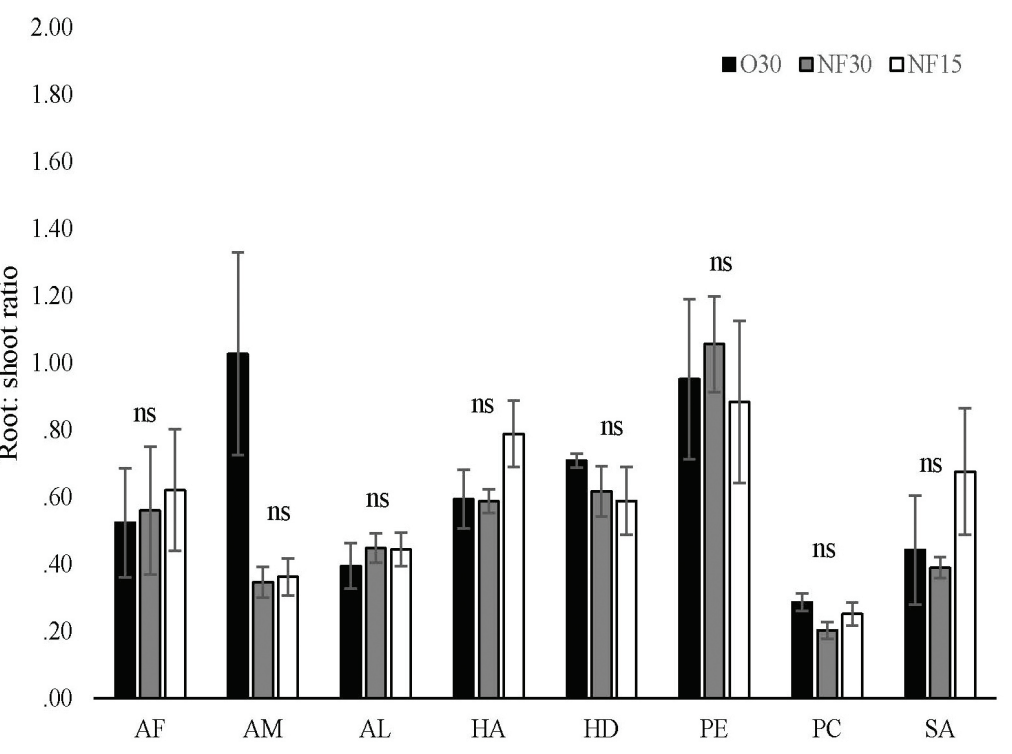

Figure 2. Effects of fertilizer treatments on mean root:shoot ratio ( \pm SE) of 8 native tree species after 121 days. Black, grey and white bars are $\mathrm{O} 30, \mathrm{NF} 30$ and $\mathrm{NF} 15$, respectively. $\mathrm{N}=3$, ns = no significant difference, $\mathrm{AF}=$ Acrocarpus fraxinifolius, $\mathrm{AM}=$ Adenanthera microsperma, $\mathrm{AL}=$ Artocarpus lacucha, $\mathrm{HD}=$ Hovenia dulcis, $\mathrm{HA}=$ Horsfieldia amygdalina, $\mathrm{PE}=$ Phyllanthus emblica, $\mathrm{PC}=$ Prunus cerasoides and $\mathrm{SA}=$ Syzygium albiflorum. 
Mean RGR-H, RGR-CW and RGR-RCD of most species: A. fraxinifolius, A. microsperma, A. lacucha, P. emblica, P. cerasoides and $S$. albiflorum, did not differ significantly among fertilizer treatments. The exceptions were $H$. amygdalina and $H$. dulcis. Mean RGR-H's of these species were also unaffected, However, mean RGR-CW and RGR-RCD of H. amygdalina with NF30 were significantly highly, at 112 days by $71 \%$ and $43 \%$ respectively, compared with those with O30 (ANOVA, $P=0.04$ and 0.04, respectively), whilst in contrast, RGR-CW of $H$. dulcis with NF15 was significantly lower, compared with that with $\mathrm{O} 30$ by $110 \%$ (ANOVA, $P=0.03$, Appendix 1).

\section{Nutrients in the medium}

In nearly all cases, $\mathrm{N}, \mathrm{P}$ and $\mathrm{K}$ levels in the potting medium did not differ significantly among the fertilizer treatments. By 112 days, differences in mean nutrient levels in the medium for most treatments and species were not significant. The few exceptions are shown in Tables 1-3 (i.e. phosphorus with Adenanthera microsperma and Syzygium albiflorum; potassium with Adenanthera microsperma and Prunus cerasoides). 


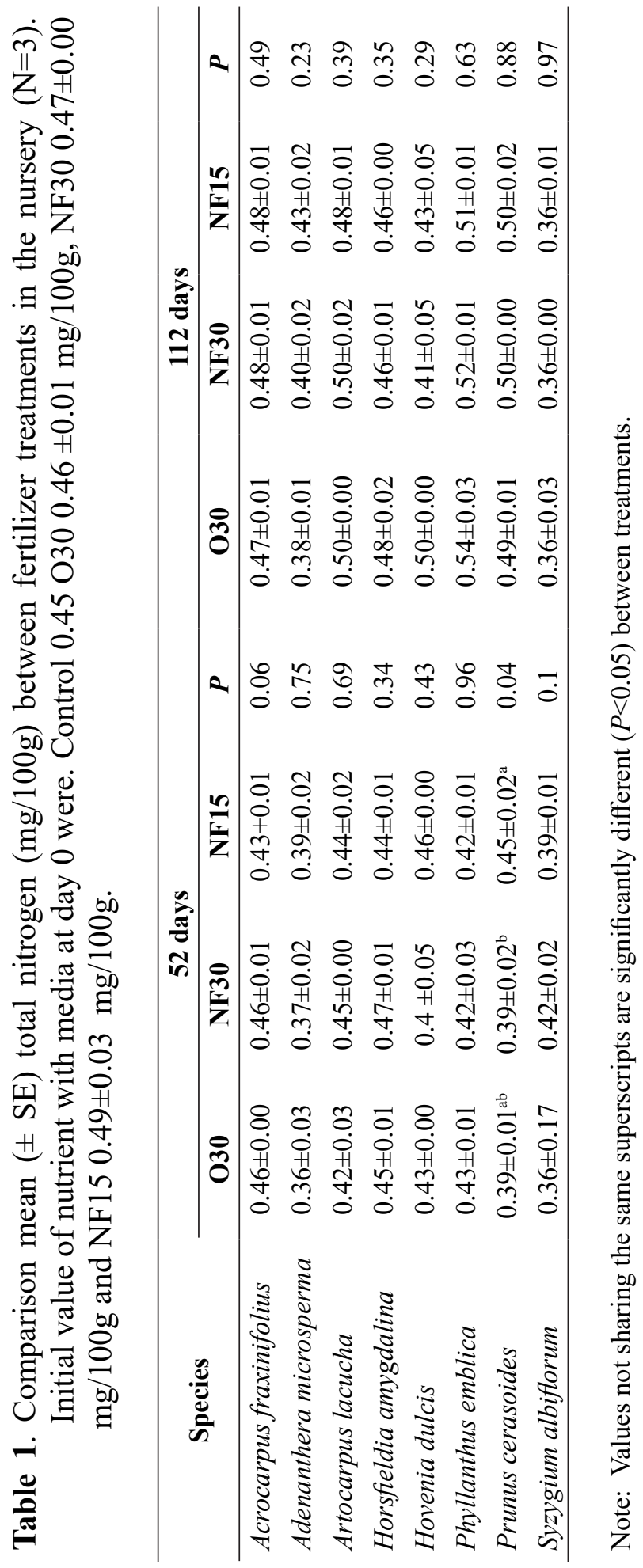




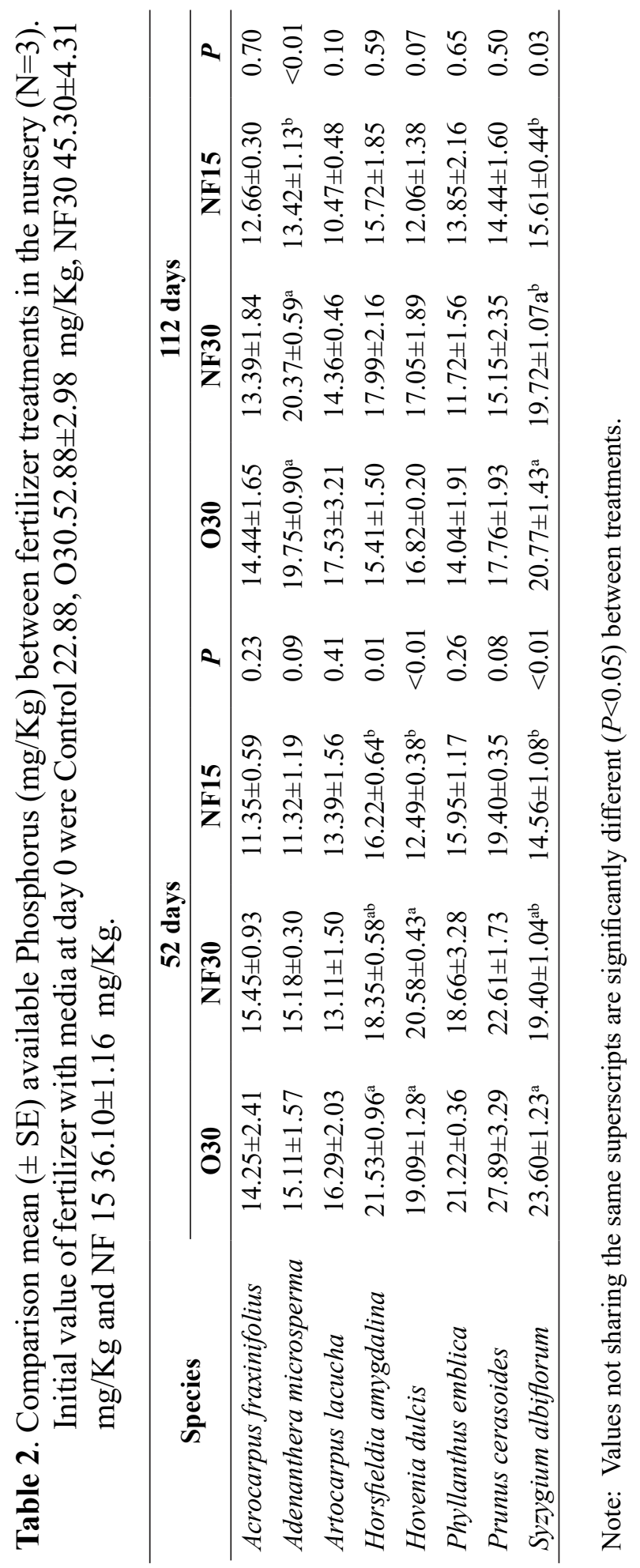




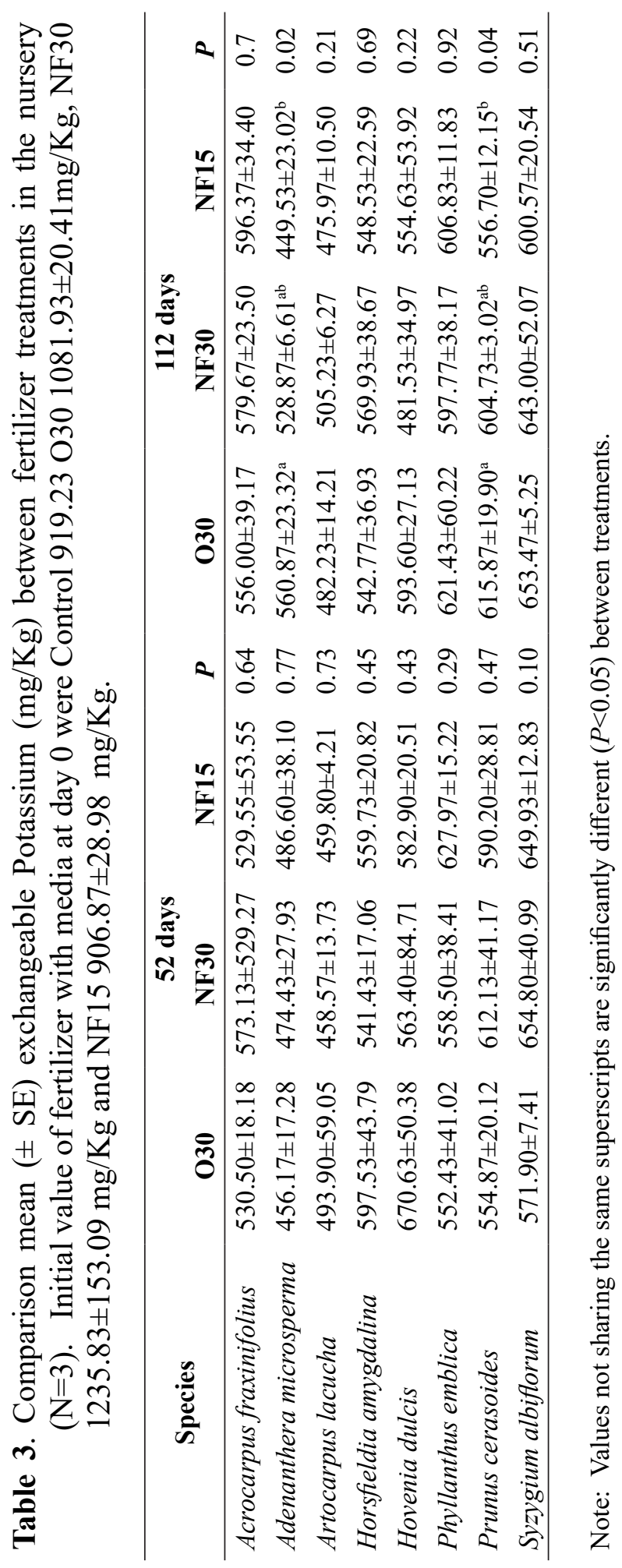




\section{DISCUSSION}

The advantages of fertilizer application, when growing planting stock of indigenous tropical forest tree species in small scale nurseries, are well known (FORRU, 2006; Hasse et al., 2014). It enables slower growing species to be grown to the optimum size for planting, by the optimum planting time (30-50 $\mathrm{cm}$ tall by the beginning of the rainy season), in less than a year. This reduces the standing-down space needed for planting stock and costs and thereby increases nursery productivity and cost efficiency.

Fertilizer trials, carried out early during development of FORRU-CMU's tree nursery, established that application of $0.3 \mathrm{~g}$ of Osmocote $^{\circledR}(13: 13: 13$ or 14:14:14), applied at 3-monthly intervals, resulted in the best growth performance for the indigenous framework tree species that are grown in the nursery (FORRU, 2006). For example, Jitlam (2001) reported that, 3-monthly applications of Osmocote $^{\circledR}$ increased RGR-H by $12 \%$ (from $158 \pm 96.6$ to $177 \pm 106.6$ ) and final height by $7 \%$ after 10 months (from $34.2 \pm 15.76$ to $36.7 \pm 17.16 \mathrm{~cm}$, averaged across all species tested), compared with soluble fertilizer ('1.5 table spoons N:P:K 15:15:15 in a 3-gallon watering can'), applied every 15 days, whilst labour costs were reduced by about $10 \%$. Singpetch (2002) obtained more mixed results, depending on species. However, three out of the five species she tested grew better with Osmocote ${ }^{\circledR}$.

Since this study showed no difference in the effect of this conventional Osmocote ${ }^{\circledR}$ fertilizer treatment and the newly developed NANOTECH fertilizer on sapling growth performance, $0.15 \mathrm{~g}$ of NANOTECH's new slow-release fertilizer could adequately replace $0.3 \mathrm{~g}$ Osmocote ${ }^{\circledR}$ without compromising productivity. A 0.3-g-dose of Osmocote ${ }^{\circledR}$ costs around 3 US cents (about 1 THB). Assuming that mass production of the NANOTECH fertilizer could be achieved at a similar or lower cost, then switching to $0.15 \mathrm{~g}$ of the NANTOTECH fertilizer would probably reduce fertilizer costs by at least $50 \%$ (1.5 US cents or about $0.5 \mathrm{THB}$ ). Since total production costs in FORRU-CMU's nursery currently amount to around 70 US cents per plant (22 THB) and most species are stood down for longer than 3 months (requiring at least two applications of the 3-month variety of Osmocote ${ }^{\circledR}$ ), the saving amounts to at least $4.3 \%$ of production costs.

Varying the partitioning of biomass, between the root and shoots, is one of the mechanisms by which plants deal with limited resources, including nutrient deficiency. Tree saplings tend to allocate a high proportion of biomass towards leaves and stems (resulting in higher photosynthetic capacity and growth potential, but also higher water demand). In contrast, in nutrient-poor conditions, where below-ground competition is dominant, tree saplings allocate a higher 
proportion of biomass to roots (leading to increased water and nutrient supply, but reduced increase in photosynthetic capacity) (Mašková \& Herben, 2018). Consequently, changes in root:shoot ratio, under different fertilizer treatments, can indicate if the treatments are affecting the balance between photosynthesis and water/nutrient supply. Ideally a root:shoot ratio of 1 , by planting day, is the ideal target that minimizes transplantation shock and maximizes post-planting seedling survival (Elliott et al., 2013). In this study, the fertilizer treatments did not significantly affect the root:shoot ratios of all species tested, suggesting that substituting O30 with NF15 would not affect post-planting sapling performance. Root:shoot ratios were similar to those reported by previous studies. For example, for Osmocote ${ }^{\circledR}$ and soluble fertilizer respectively, Jitlam (2001) reported root:shoot ratios of $0.54 \& 0.72$ for A. lacucha and $0.56 \& 0.65$ for $H$. amygdalina saplings, grown in the same nursery and using the same medium and container type/size. Corresponding values in our study (for O30, NF30, NF15, respectively) were $0.39,0.45 \& 0.44$ for A. lacucha and $0.59,0.59 \& 0.79$ for H. amygdalina. Zangkum (1998) also reported similar root:shoot ratios for several other species of similar age, grown in the same nursery under identical conditions. Although the root:shoot ratios by day 121 (December) were mostly below the ideal target of 1 (Figure 2), the ratio was increasing with increasing sapling age of all species, suggesting that a ratio closer to 1 would be achieved by planting time (June).

The dynamics of nutrient retention in the potting medium varied among the 3 elements tested. The fertilizer treatments appeared to have maintained $\mathrm{N}$ supply (Table 1), with nutrient release balancing nutrient uptake by the plants and wash out. In contrast, $\mathrm{P}$ and $\mathrm{K}$ levels had halved or declined by more than half by 52-121 days, indicating that nutrient uptake by the plants and/or washout exceeded nutrients released by the fertilizer. Further research is recommended on how the nature of the potting medium (which contains $50 \%$ added organic matter) may be affecting cation exchange capacity and the mobility of nutrients and thus determine how changing the potting medium mix might be done to increase the effectiveness of the fertilizer applied.

$P$. cerasoides grew exceptionally well under the experimental conditions, compared with the other species growing taller than $30 \mathrm{~cm}$ by 121 days after potting (December). FORRU (2006) recommends an out-planting size of about $30 \mathrm{~cm}$ for fast-growing pioneer trees such as $P$. cerasoides. So, this species may require pruning or reduced fertilizer application to prevent it from outgrowing its container by June. P. cerasoides is one of the most effective framework tree species, whether it is established by direct seeding (Waiboonya, 2017) or conventional tree planting (Elliott et al., 2003), as it has high rates of survival 
and growth and produces cherries that are highly attractive to seed-dispersing birds within 3 years after planting. Its ease of propagation in the nursery adds to its acceptability as a framework tree species. It therefore stands out as being exceptionally suitable for inclusion in mixtures of tree species planted to restore upland evergreen forest in northern Thailand.

\section{CONCLUSION}

The newly developed fertilizer (NANOTECH fertilizer) was at least as good as the standard fertilizer regime in terms of sapling performance (growth, biomass and root-shoot ratio). Since it can be applied at half the regular dose, its use is likely to be more cost-effective than continued use of Osmocote ${ }^{\circledR}$, provided that it can be mass produced at a retail cost that is not higher than that of Osmocote ${ }^{\circledR}$.

\section{ACKNOWLEDGEMENTS}

We thank the Graduate School and Faculty of Science for granting this research project, the National Nanotechnology Centre (NANOTEC) for supporting media analysis, FORRU-CMU for use of nurseries, staff assistance, tools and equipment.

\section{REFERENCES}

Elliott, S., Navakitbumrung, P., Kuarak, C., Zangkum, S., Anusarnsunthorn, V., and Blakesley, D. 2003. Selecting framework tree species for restoring seasonally dry tropical forests in northern Thailand based on field performance. Forest Ecology and Management. 184: 177-191. https:// doi.org/10.1016/S0378-1127(03)00211-1

Elliott, S.D., Blakesley, D., and Hardwick, K. 2013. Restoring tropical forest: a practical guide. Royal Botanic Garden, Kew. London: Kew Publishing. $344 \mathrm{pp}$.

FORRU (Forest Restoration Research Unit). 2006. How to plant a forest: the principles and practice of restoring tropical forests. Department of Biology, Faculty of Science, Chiang Mai University, Chiang Mai. Goosem, S.P., and Tucker, N.I.J. 1995. Repairing the rain forest: Theory and practice of rainforest re-establishment in North Queensland's wet tropics. Cairns: Wet Tropics Management Authority. 71 pp. 
Haase, D.L., Landis, T.D., and Dumroese, R.K. 2014. Outplanting. In: Wilkinson, K.M., Landis, T.D., Haase, D.L., Daley, B.F., and Dumroese, R.K. editors. Tropical nursery manual a guide to starting and operating a nursery for native and traditional plants. United States: Department of Agriculture.

Hammer, Ø., Harper, D.A.T., and Ryan, P.D. 2001. PAST: Paleontological statistics software package for education and data analysis. Palaeontologia Electronica. 4(1): 4-9.

Jantawong, K., Elliott, S., and Wangpakapattanawong, P. 2017. Above-ground carbon sequestration during restoration of upland evergreen forest in northern Thailand. Open Journal of Forestry. 7: 157-171.

Jitlam, N. 2001. Effects of container type, fertilizer and air pruning on the propagation of tree seedlings for forest restoration (master's thesis). Chiang Mai: Chiang Mai University.

Kavinchan, N., Wangpakapattanawong, P., Elliott, S., Chairuangsri, S., and Pinthong, J. 2015. Use of the framework species method to restore carbon flow via litterfall and decomposition in an evergreen tropical forest ecosystem, northern Thailand. Kasetsart Journal (Natural Science). 49: 639-650.

Mašková, T., and Herben, T. 2018. Root:shoot ratio in developing seedlings: How seedlings change their allocation in response to seed mass and ambient nutrient supply. Ecology and Evolution. 8(14): 7143-7150. https://doi.org/10.1002/ece3.4238

Singpetch, S. 2002. Propagation and growth of potential framework tree species for forest restoration (master's thesis). Chiang Mai: Chiang Mai University.

Sitthisuwannakul1, K., Boonpavanitchakul, K., Muthitamongkol, P., and Kangwansupamonkon, W. 2014. Polymer-layered silicate nanocomposite for slow released fertilizer. The $4^{\text {th }}$ Thailand International Nanotechnology Conference 2014; 2014 November 26-28; Convention center, Thailand Science Park, Pathumthani: Thailand.

Waiboonya, P. 2017. Development of new techniques of seed storage and direct seeding of native tree species for tropical forest restoration (dissertation). Chiang Mai: Chiang Mai University.

Wydhayagarn, C., Elliott, S., and Wangpakapattanawong, P. 2009. Bird communities and seedling recruitment in restoring seasonally dry forest using the framework species method in northern Thailand. New Forests. 38: 81-97. https://doi.org/10.1007/s11056-009-9133-z

Zangkum, S., 1998. The effects of container type and media on growth and morphology of tree seedlings to restore forests (master's thesis). Chiang Mai: Chiang Mai University. 


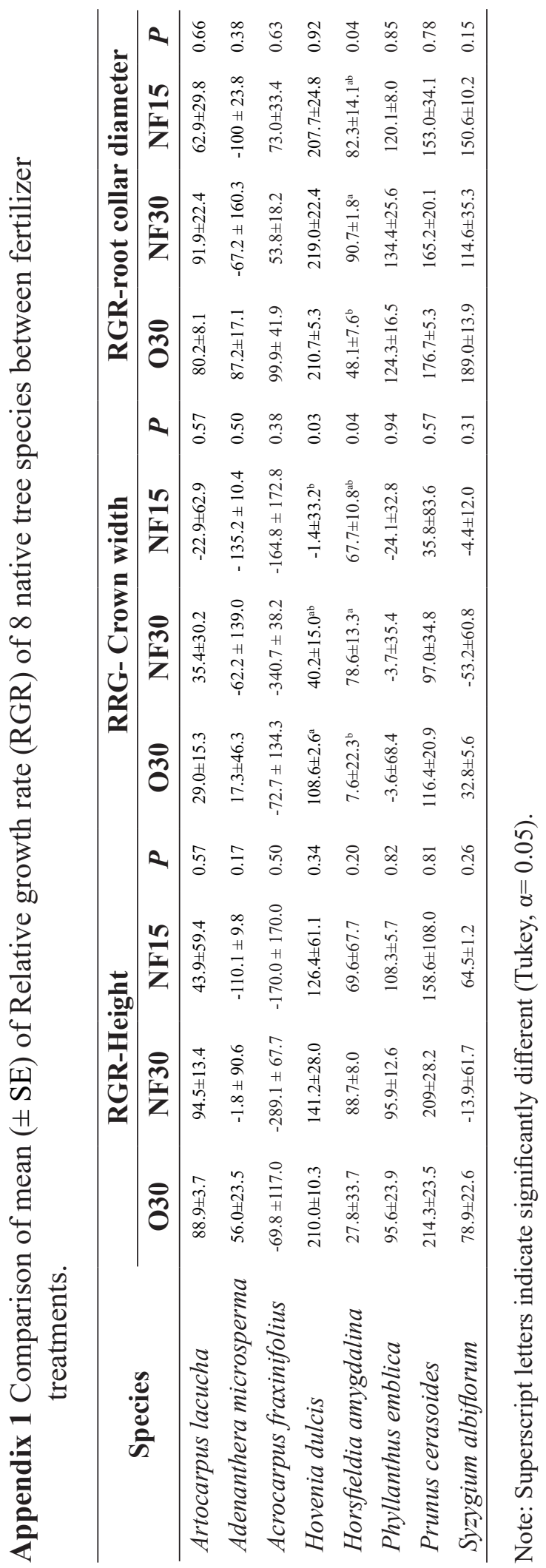

